\title{
Bias in retrospective studies of trends in asthma incidence
}

\author{
J. Brogger*, T. Eagan*, G.E. Eide", P. Bakke*, A. Gulsvik*
}

Bias in retrospective studies of trends in asthma incidence. J. Brogger, T. Eagan, G.E. Eide, P. Bakke, A. Gulsvik. C) ERS Journals Ltd 2004.

ABSTRACT: There is evidence for an increase in adult asthma prevalence. Several retrospective studies have shown an increase in asthma incidence by year of birth, consistent with an increasing trend in asthma incidence.

The validity of this retrospective approach is unknown. Retrospective and prospective asthma incidence by year of birth were compared in the same community, during the same time period, from two independent studies; a cohort study and a cross-sectional study in Western Norway. In the prospective study, subjects without asthma were followed from 1985-1996/1997. In the retrospective study in 1998, subjects reported the age at which the disease started. Analyses of incident asthma in the period 1985-1996 were compared between the studies.

The retrospective analysis showed a large increase in asthma incidence by year of birth, with an odds ratio (OR) of 2.9 comparing those born in 1969 with those born in 1927. The prospective study showed the opposite, with an OR of 0.2 comparing those born in 1969 with those born in 1927 . There was only a $20 \%$ difference in the cumulative incidence of asthma.

To conclude, retrospective estimates of trends in asthma incidence are likely to be severely biased by differential recall.

Eur Respir J 2004; 23: 281-286.
*Dept of Thoracic Medicine, Institute of Medicine, University of Bergen, and ${ }^{\#}$ Centre for Clinical Research, Haukeland University Hospital, and Section for Epidemiology and Medical Statistics, Dept of Public Health and Primary Health Care, University of Bergen, Bergen, Norway.

Correspondence: J. Brogger, Dept of Thoracic Medicine, Haukeland University Hospital, N-5021 Bergen, Norway.

Fax: 4755975149

E-mail: jan.brogger@med.uib.no

Keywords: Asthma/epidemiology, bias (epidemiology), epidemiology/trends, incidence, retrospective studies

Received: April 112003

Accepted after revision: September 212003

The study was supported by the Norwegian Research Council and the University of Bergen.
A number of studies of various designs have documented a long-term increase in asthma prevalence in children [1-5] and to a certain extent in adults [6-16]. It is uncertain whether this represents an increase in incidence or a longer duration of disease. Aetiological theories have been formed to explain the increase in asthma. Confirming an increase in asthma incidence as the cause of increasing asthma prevalence is important [17].

The evidence to suggest an increase in asthma incidence remains soft, based largely on healthcare usage statistics [18-22] or mortality [23-27]. Population-based prospective studies of long-term trends in asthma incidence are scarce [28, 29]. Several studies have used retrospective age-of-onset data to document changes in asthma incidence over the long term [30-32]. SUNYER et al. [30] were able to show an increase in the incidence of asthma in Europe by year of birth, by asking subjects retrospectively about their age at first asthma attack. DE MARCO et al. [31] used the same data to show a sex reversal in asthma incidence at puberty. In a separate Italian study, DE MARCO et al. [32] also showed an increase in asthma incidence with year of birth. These two studies appear to be an important basis for the perception of an increase in asthma incidence. The validity of a retrospective analysis as used in these studies is unknown.

In the present paper, a prospective cohort study was used as a gold standard, and this was compared with two different retrospective estimates of asthma and bronchitis incidence. The studies covered the same population, the same geographical area and the same time period. Retrospective estimates came from an independent cross-sectional study in 1998, and from a retrospective analysis of the last follow-up of the cohort study.The objective of this paper was to assess the validity of a retrospective analysis of trends in asthma incidence, by using the prospective study as a gold standard.

\section{Methods}

Previous papers report the study design and data collection of the baseline [33], the follow-up [34] of the prospective study, and the cross-sectional study [35-37]. For comparison between studies, only subjects born from 1927-1969, living in the city of Bergen and 11 surrounding municipalities, were eligible for the analyses. Both studies were based on random population samples of the adult population aged 15-70 yrs. The sampling for each study was done independently. Age was computed as of January 1, 1985.

Briefly, the prospective study was conducted between 1985-1996/1997. Of the 3,129 subjects who were eligible in $1985,2,427$ subjects responded to a postal questionnaire both at baseline and follow-up. In the retrospective study, 2,864 subjects were eligible. Data were collected through a postal questionnaire in 1998/1999, with a telephone follow-up for nonresponders. In previous studies, good comparability was found between postal and telephone survey modes [35], with little evidence of nonresponse bias [38]. There was minimal overlap between the two samples. Sampling fractions were $<2 \%$ in both studies, such that 47 subjects were sampled into both studies. Of these, 24 were responders and are included in the data analysed. 


\section{Questionnaire and definitions}

Asthma and bronchitis diagnosis was defined in both studies as a positive response to the question "Have you ever been treated by a doctor or been admitted to hospital for one of the diseases mentioned below?", "Asthma?", "Bronchitis?": "Yes" or "No." In the independent retrospective study and the retrospective analysis in the cohort study, the time of onset for each diagnosis was defined as the response to the question "How old were you when the disease started?" This time of onset was used to characterise incident asthma between 1985-1996.

In the prospective study, an incident asthma or bronchitis case was a person who reported no asthma or bronchitis in 1985 and reported asthma or bronchitis in 1996. Those who answered "don't know" to the questions on asthma or bronchitis at any time were excluded.

To ensure comparability between studies, smoking habits in the prospective study were defined on the basis of the information given in the follow-up, not baseline. Smoking habits were defined in the same way in both studies.

\section{Statistical analysis}

Age, sex and smoking habits were compared between the prospective cohort study and the independent retrospective study using a t-test and a Chi-squared test, respectively (table 1). Due to nonindependence of observations when comparing estimates within the same study, the retrospective analysis of the cohort study only reported cumulative incidence (table 2). The remaining analysis compared the independent retrospective study with the gold standard prospective study. This was performed in two parts, first for cumulative incidence (table 2) and then for incidence by year of birth (table 3 ). Each of these analyses computed an overall estimate, and then looked for subgroups with different effects. The analysis of subgroup effects first used a global test for any differences in subgroups (significance level of 0.05 ). If this test was significant, then any interactions were retained at a significance level of 0.05 . Effects were estimated with logistic regression.

Cumulative incidence was compared between the prospective and the retrospective studies, overall, and in subgroups defined by smoking and sex. A smoothed estimate of the effect of year of birth on incidence was computed with generalised additive logistic regression using a smoothing spline with 3 degrees of freedom [39, 40]. The fitted log odds curves were scaled so that 1927 had an odds ratio (OR) of 1. A more conventional categorical analysis was then performed of the effect of year of birth. This analysis was carried out overall, and separately in subgroups defined by sex and smoking.

The comparison of retrospective and prospective estimates within the same study accounted for nonindependence. Observations missing data in 1996/1997 were excluded. Estimates of cumulative incidence were computed retrospectively and prospectively. For the statistical testing, each study person was their own pair, contributing a retrospective and prospective estimate of asthma status in 1985. If the retrospective and prospective estimates were the same, then this table should be symmetric. Hence, a test of symmetry was performed. This analysis used a $3 \times 3$ table for the values asthma, no asthma and missing data.

\section{Results}

In the prospective study, $77.6 \%$ of the original 3,129 subjects were responders in both the baseline and follow-up study. The response rate in the retrospective study was $88.3 \%$ (table 1). The responders were comparable in age, sex and smoking habit.

A comparison of the cumulative 11-yr incidence of asthma and bronchitis in the prospective study and retrospective study is given in table 2 . Overall, there was a $20-60 \%$ difference in the cumulative incidence of asthma. Taking the prospective study as the gold standard, the retrospective analyses gave an underestimate as expected. In the independent retrospective study, there was a large underestimation of asthma incidence for males, but little difference according

Table 1. - Exclusions and demographic characteristics of responders in two studies: a prospective study from 1985-1996/1997 and a retrospective study in 1998

\begin{tabular}{|c|c|c|c|c|c|}
\hline & $\mathrm{PCS}^{\#}$ & GSPA & RA & IRS & p-value \\
\hline Sample size & 3129 & & & 2864 & \\
\hline Nonresponders at baseline & 347 & & & 598 & \\
\hline Nonresponders at follow-up or died & 355 & & & N/A & \\
\hline Responders & 2427 & & & 2266 & \\
\hline Mean age yrs & 33.6 & & & 33.6 & 0.98 \\
\hline Males \% & 50.9 & & & 50.8 & 0.96 \\
\hline Current smokers at follow-up $\%$ & 35.6 & & & 38.1 & \\
\hline Exsmokers at follow-up \% & 26.8 & & & 23.8 & 0.49 \\
\hline \multicolumn{6}{|l|}{ Asthma } \\
\hline Onset before 1985 & & 71 & 68 & 90 & \\
\hline Missing data at baseline or follow-up & & 115 & 96 & 119 & \\
\hline Eligible for incidence $1985-1996 / 1997$ & & 2241 & 2263 & 2057 & \\
\hline Incident cases & & 81 & 47 & 59 & \\
\hline \multicolumn{6}{|l|}{ Bronchitis } \\
\hline Onset before 1985 & & 425 & 247 & 291 & \\
\hline Missing data at baseline or follow-up & & 290 & 365 & 413 & \\
\hline Eligible for incidence 1985-1996/97 & & 1712 & 1815 & 1562 & \\
\hline Incident cases & & 199 & 110 & 96 & \\
\hline
\end{tabular}

Data are presented as $\mathrm{n}$ unless otherwise stated. PCS: prospective cohort study; GSPA: gold standard prospective analysis; RA: retrospective analysis; IRS: independent retrospective study; N/A: not applicable. ${ }^{\#}$ : the prospective study includes the gold standard prospective analysis, as well as a retrospective analysis using only age-of-onset data from 1996/1997; ": as of January 1st 1985. The table shows the asthma and bronchitis incidence among subjects born 1927-1969 in Bergen, Norway, and surrounding areas. 
Table 2. - A comparison of retrospective and prospective estimates of cumulative asthma and bronchitis incidence

\begin{tabular}{|c|c|c|c|c|c|c|}
\hline & $\begin{array}{l}\text { GSPA in cohort } \\
\text { study } \%\end{array}$ & $\begin{array}{l}\text { RA in cohort } \\
\text { study } \%\end{array}$ & p-value ${ }^{\#}$ & IRS \% & $\mathrm{OR}^{\top}(95 \% \mathrm{CI})$ & p-value \\
\hline \multicolumn{7}{|l|}{ Asthma } \\
\hline $\mathrm{M}$ & 3.7 & 2.0 & 0.03 & 1.4 & $2.68(1.29-5.53)$ & $<0.01$ \\
\hline $\mathrm{F}$ & 3.6 & 2.2 & 0.06 & 4.5 & $0.79(0.50-1.25)$ & 0.31 \\
\hline \multicolumn{7}{|l|}{ Year of birth } \\
\hline 1927-1939 & 5.3 & 2.9 & 0.81 & 2.0 & $2.81(1.29-6.13)$ & $<0.01$ \\
\hline $1940-1959$ & 3.4 & 1.9 & 0.02 & 3.0 & $1.17(0.68-2.02)$ & 0.58 \\
\hline 1960-1969 & 2.7 & 1.8 & 0.09 & 3.6 & $0.75(0.38-1.48)$ & 0.41 \\
\hline \multicolumn{7}{|l|}{ Smoking habit } \\
\hline Never-smokers & 3.3 & 2.2 & 0.09 & 3.0 & $1.08(0.57-2.06)$ & 0.82 \\
\hline Exsmokers & 4.2 & 2.7 & 0.41 & 3.9 & $1.08(0.55-2.13)$ & 0.82 \\
\hline Total & 3.6 & 2.1 & $<0.005$ & 3.0 & $1.23(0.85-1.79)$ & 0.27 \\
\hline \multicolumn{7}{|l|}{ Bronchitis } \\
\hline $\mathrm{M}$ & 8.5 & 3.4 & $<0.001$ & 4.5 & $1.97(1.16-3.34)$ & 0.01 \\
\hline $\mathrm{F}$ & 14.8 & 8.6 & $<0.001$ & 10.2 & $1.53(1.07-2.18)$ & 0.02 \\
\hline \multicolumn{7}{|l|}{ Year of birth } \\
\hline $1927-1939$ & 14.4 & 6.5 & 0.04 & 7.9 & $1.97(1.00-3.90)$ & 0.05 \\
\hline $1940-1959$ & 10.6 & 5.6 & $<0.001$ & 6.6 & $1.67(1.07-2.61)$ & 0.02 \\
\hline 1960-1969 & 11.6 & 6.5 & $<0.005$ & 8.0 & $1.50(0.94-2.40)$ & 0.09 \\
\hline \multicolumn{7}{|l|}{ Smoking habit } \\
\hline Never-smokers & 9.3 & 5.3 & $<0.005$ & 5.8 & $1.66(1.00-2.74)$ & 0.05 \\
\hline Exsmokers & 13.1 & 5.1 & $<0.001$ & 5.0 & $2.88(1.53-5.41)$ & $<0.01$ \\
\hline Current smokers & 13.3 & 7.7 & $<0.001$ & 10.3 & $1.34(0.86-2.09)$ & 0.19 \\
\hline Total & 11.6 & 6.1 & $<0.001$ & 7.3 & $1.67(1.25-2.24)$ & $<0.001$ \\
\hline
\end{tabular}

GSPA: gold standard prospective analysis; RA: retrospective analysis; IRS: independent retrospective study; OR: odds ratio; CI: confidence interval; M: male; F: female. ${ }^{\#}$ : comparing retrospective and prospective estimates within the same study; ${ }^{\uparrow}$ : comparing retrospective and prospective estimates from independent studies (the retrospective study is the reference group). Table shows the incidence by sex, age, smoking habit and year of birth in a prospective and a retrospective study of asthma incidence from 1985-1996/1997 among subjects born 1927-1969 in Bergen, Norway, and surrounding areas.

to smoking habit. Older birth cohorts had an underestimate of asthma incidence, while younger birth cohorts had an overestimate. For asthma, the subgroup analysis showed that there was a difference in the degree of bias among males and females (final p-value 0.0053). In the retrospective analysis within the prospective study, all birth cohorts gave an underestimate of asthma incidence. The retrospective study underestimated bronchitis incidence overall. The subgroup analysis showed that this degree of bias was significantly different according to smoking habit $(\mathrm{p}=0.0019)$.

The smoothed OR of incident asthma in the period 1985-1997 by year of birth is shown in figure 1. Those born in 1927 were the reference category (OR 1). There was a large discrepancy between the independent retrospective and the

Table 3. - Odds ratios (OR) of asthma incidence by year of birth overall and by sex and smoking habit in a prospective and a retrospective study from 1985-1996/1997 among subjects born 1927-1969 in Bergen, Norway and surrounding areas

\begin{tabular}{|c|c|c|c|c|c|}
\hline & \multirow[t]{2}{*}{ Year of birth } & \multirow[t]{2}{*}{ GSPS OR } & \multirow[t]{2}{*}{ IRS OR } & \multicolumn{2}{|c|}{ Difference between studies } \\
\hline & & & & OR $(95 \% \mathrm{CI})$ & $\mathrm{p}$-value \\
\hline \multirow[t]{3}{*}{ M } & $1927-1939$ & $1^{\#}$ & $1^{\#}$ & $0.14(0.03-0.61)$ & \multirow[t]{3}{*}{$<0.005$} \\
\hline & $1940-1959$ & 0.55 & 0.92 & $0.24(0.09-0.63)$ & \\
\hline & $1960-1969$ & 0.35 & 2.75 & $1.10(0.31-3.85)$ & \\
\hline \multirow[t]{3}{*}{$\mathrm{F}$} & $1927-1939$ & $1^{\#}$ & $1^{\#}$ & $0.53(0.20-1.39)$ & \multirow[t]{3}{*}{0.29} \\
\hline & $1940-1959$ & 0.73 & 1.83 & $1.46(0.74-2.88)$ & \\
\hline & $1960-1969$ & 0.69 & 1.71 & $1.45(0.66-3.19)$ & \\
\hline \multicolumn{6}{|l|}{ Smoking habit } \\
\hline \multirow[t]{3}{*}{ Never-smokers } & $1927-1939$ & $1^{\#}$ & $1^{\#}$ & $0.16(0.03-0.75)$ & \multirow[t]{3}{*}{0.09} \\
\hline & $1940-1959$ & 0.49 & 2.58 & $0.89(0.35-2.24)$ & \\
\hline & $1960-1969$ & 0.27 & 2.95 & $1.84(0.55-6.12)$ & \\
\hline \multirow[t]{3}{*}{ Exsmokers } & $1927-1939$ & $1^{\#}$ & $1^{\#}$ & $0.32(0.06-1.62)$ & \multirow[t]{3}{*}{0.58} \\
\hline & $1940-1959$ & 1.03 & 3.45 & $1.13(0.46-2.78)$ & \\
\hline & $1960-1969$ & 1.06 & 3.01 & $0.96(0.27-3.44)$ & \\
\hline \multirow[t]{3}{*}{ Current smokers } & $1927-1939$ & $1^{\#}$ & $1^{\#}$ & $0.53(0.18-1.59)$ & \multirow[t]{3}{*}{0.44} \\
\hline & $1940-1959$ & 0.49 & 0.49 & $0.56(0.21-1.49)$ & \\
\hline & $1960-1969$ & 0.51 & 1.06 & $1.15(0.42-3.13)$ & \\
\hline \multirow[t]{3}{*}{ Overall } & $1927-1939$ & $1^{\#}$ & $1^{\#}$ & $0.32(0.15-0.70)$ & \multirow[t]{3}{*}{0.03} \\
\hline & $1940-1959$ & 0.64 & 1.53 & $0.83(0.48-1.43)$ & \\
\hline & $1960-1969$ & 0.50 & 1.88 & $1.28(0.65-2.52)$ & \\
\hline
\end{tabular}

GSPS: gold standard prospective study; IRS: independent retrospective study; CI: confidence interval; M: male; F: female. ${ }^{\#}$ : reference. The birth cohort 1927-1939 is the reference group within each study. The prospective study is the reference group for the differences between studies. 

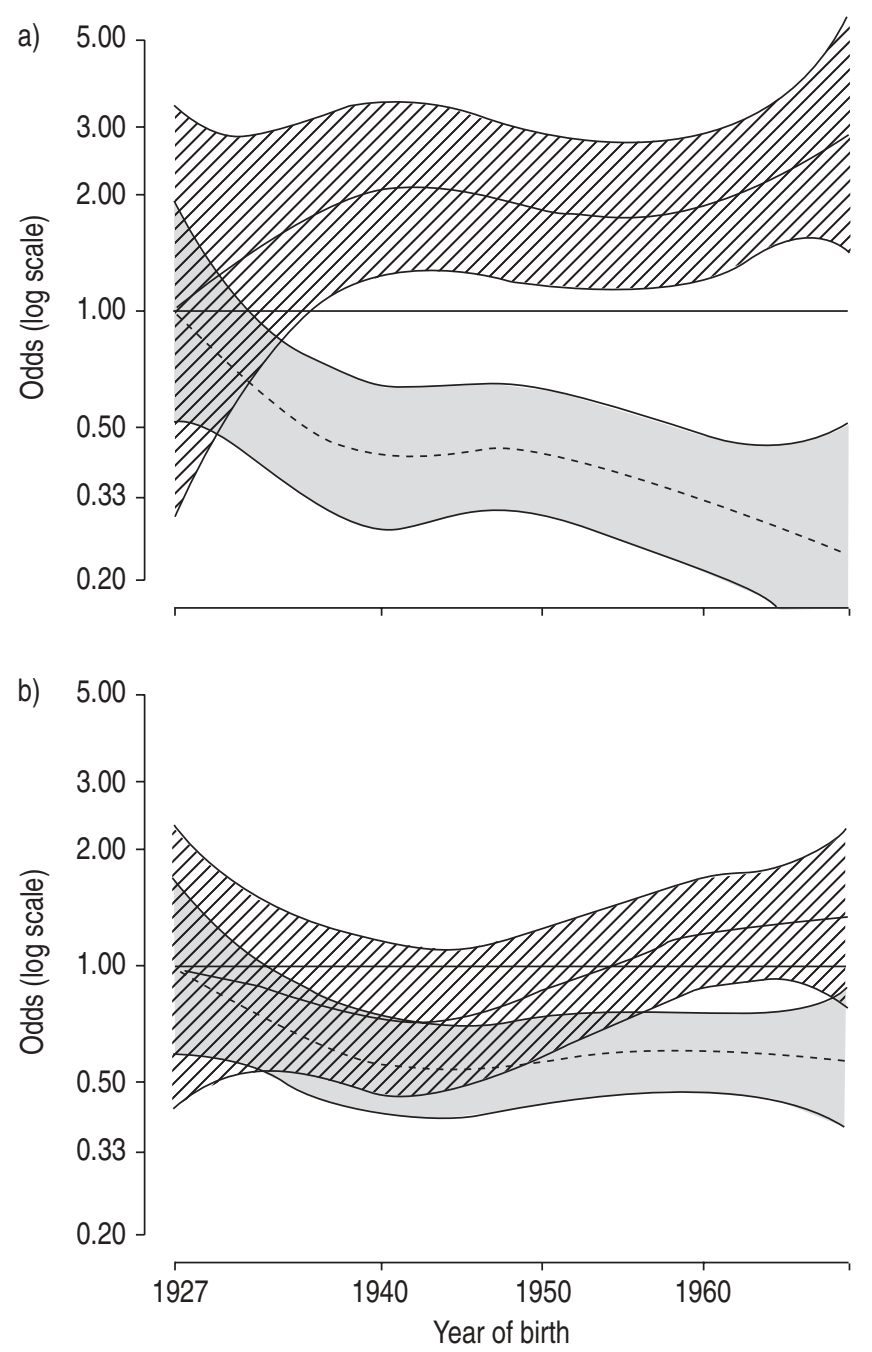

Fig. 1. - Odds of incident a) asthma and b) bronchitis by year of birth

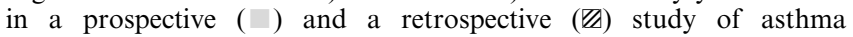
incidence from 1985-1996/1997 among subjects born 1927-1969 in Bergen, Norway and surrounding areas. Estimated with a generalised additive logistic regression with a 3 degrees of freedom smoothing spline. Shaded areas represents \pm 2 SE. Each curve has been scaled so that the year of birth 1927 is the reference group.

prospective estimates of the effect of year of birth. In fact, conclusions from either type of analysis would be exactly opposite. The OR comparing those born in 1969 with those in 1927 was 2.89 in the retrospective study, and 0.23 in the prospective study. The bias was less severe for bronchitis, but in the same direction as for asthma. The same trends were evident when this figure was produced for subgroups of males, females, never-smokers, exsmokers and current smokers.

The ORs of asthma by year of birth in different subgroups are given in table 3 . The prospective study showed a decrease in asthma incidence with year of birth in all these groups, while the independent retrospective study gave the opposite conclusion. The subgroup analysis did not reveal any significantly different subgroups ( $\mathrm{p}$-value for any interaction $0.68)$.

Missing answers to a question may indicate recall bias. In table 4 the proportion of missing answers to questions on diagnosis and onset of disease by year of birth is shown. In the independent retrospective cross-sectional study in 1998, there was clear evidence of increasing uncertainty in questions on diagnosis by year of birth. For questions on asthma onset, there was a large proportion of missing answers in those born before 1940. For onset of bronchitis, the proportion of missing answers was large in all birth cohorts. There is much less evidence of such a trend in either of the two surveys in the prospective study.

\section{Discussion}

Asthma incidence has been shown to be underestimated by using age-of-onset data retrospectively. There was a severe bias when these retrospective data were used to study trends in asthma incidence by year of birth. This calls into question the previous retrospective studies that have shown increasing trends in asthma incidence.

Researchers interpreting a retrospective incidence study should always wonder "what if" a prospective study had been performed instead. The strength of the present study is that it provides that contrast, since the two studies are independent and cover the same age groups and geographic area. The studies are performed in the way that retrospective and prospective incidence studies are usually performed. It is an additional strength that the findings have been replicated by a retrospective analysis within the prospective cohort.

The data has been analysed and looked at for age and cohort effects. Analyses of trends in disease should ideally look for age, period and cohort effects simultaneously. This is not possible unless there are more than two time points [41]. Since previous retrospective studies of trends in asthma incidence have looked for age-cohort effects, the same have been chosen here.

Table 4.-Percentages of missing answers to questions on asthma, onset of asthma, bronchitis and onset of bronchitis by year of birth in a prospective and a retrospective study of asthma

\begin{tabular}{|c|c|c|c|c|c|}
\hline & & \multicolumn{3}{|c|}{ Year of birth } & \multirow[t]{2}{*}{ p-value } \\
\hline & & $1927-1939$ & $1940-1959$ & 1960-1969 & \\
\hline $\mathrm{R} / \mathrm{P} \mathrm{n}$ & & $498 / 497$ & $1096 / 1226$ & $672 / 704$ & \\
\hline \multirow{2}{*}{$\mathrm{P}$} & Asthma diagnosis in 1985 & 2.4 & 2.4 & 1.4 & 0.29 \\
\hline & Asthma diagnosis in 1997 & 3.6 & 2.8 & 3.1 & 0.64 \\
\hline \multirow[t]{2}{*}{$\mathrm{R}$} & Asthma diagnosis & 8.9 & 2.8 & 3.1 & $<0.0001$ \\
\hline & Asthma onset ${ }^{\#}$ & 22.6 & 5.6 & 3.2 & 0.0061 \\
\hline \multirow[t]{2}{*}{$\mathrm{P}$} & Bronchitis diagnosis in 1985 & 3.4 & 4.3 & 5.0 & 0.43 \\
\hline & Bronchitis diagnosis in 1997 & 12.5 & 10.4 & 11.2 & 0.47 \\
\hline \multirow[t]{2}{*}{$\mathrm{R}$} & Bronchitis diagnosis & 19.4 & 11.5 & 11.9 & 0.0001 \\
\hline & Bronchitis onset $^{\#}$ & 17.6 & 16.3 & 15.6 & 0.92 \\
\hline
\end{tabular}

Data are presented as per cent unless otherwise stated. R: retrospective; P: prospective. ${ }^{\#}$ : among those with a positive answer to the diagnosis. Table shows the incidence from 1985-1996/1997 among subjects born 1927-1969 in Bergen, Norway and surrounding areas. 
It is an open question whether the "start of the disease" can be defined accurately for asthma, and recalled correctly. The European Community Respiratory Health Survey asked for "age at first asthma attack" [30]. This is perhaps more vividly remembered than the authors' term "age at start of disease". Another Swedish retrospective study used "year of asthma diagnosis" [42]. Little is known about the validity of any of these questions, or their merit relative to each other.

The major problem with using retrospective reports of disease onset to estimate incidence is the frailty of human memory. DODGE and BurRows [43] found somewhat similar estimates of asthma incidence when they compared prospective and retrospective estimates in the young, but retrospective estimates failed to show an increase in elderly females that was, however, found prospectively. STRACHAN et al. [44] found retrospective estimates of asthma incidence that were $60 \%$ lower than the true prospective estimates, and a substantial proportion of adult subjects had forgotten any childhood asthma.

SUNYER et al. [30] showed retrospectively an increase in the incidence of asthma by year of birth. Their report also included the region from which the present studies were drawn (Hordaland, Norway). They reported no increase in incidence of asthma in Hordaland. This is no doubt in part due to a smaller sample size. The most important factor is probably that their birth cohort started in 1945 and ended in 1971, whereas the present cohort started in 1927.

A comparable Swedish study [42] used the same retrospective method to investigate risk factors for adult-onset asthma, but found little apparent increase with year of birth. If there was a recall bias in this study as well, the neutral trend found in the study could in fact obscure a decreasing trend in asthma incidence.

While the overall asthma incidence was underestimated by only $20 \%$, there was weak evidence of a stronger bias in subgroups. The present study had limited power for such an analysis. However, the degree of bias in males was such that retrospective estimates of asthma incidence must be considered suspect until further data can corroborate or disprove these findings.

The bias in the retrospective study was stronger in older birth cohorts. This may indicate poorer recall in general, but may also indicate different attitudes to healthcare in general and asthma specifically.

Some weaknesses must be acknowledged. The prospective study is used as the "gold standard" against which the retrospective study is compared. However, it is possible that there is some nonresponse bias in this study. The prevalence of an answer of "don't know" to questions on diagnosis at baseline in 1985 was nearly the same as the prevalence of asthma diagnosis $(2.14 \%, \mathrm{n}=52$ versus $2.93 \%, \mathrm{n}=71)$. These subjects may be at higher risk of incident asthma during follow-up. Of these 52 subjects, five $(10 \%)$ answered that they had asthma in 1996/1997. This cumulative incidence is higher than among those who answered "no" in 1985. However, the numbers were not high enough to have any significant impact on the cumulative incidence.

There is also the possibility that there were "interval cases" in the prospective study, i.e. asthma or bronchitis cases who only had asthma for a short period between baseline and follow-up. These may have been "picked up" in the retrospective study, thus leading to a bias, but this is unlikely.

The follow-up in the prospective study lasted from September 1996 to May 1997. To ensure comparable follow-up in the retrospective study, only cases of incident asthma between 1985-1996 were included. Some retrospective cases that occurred in 1997 were thus excluded that should have been included; if they had occurred from January to May 1997. As there were only seven cases of incident asthma in all of 1997 this is unlikely to have affected results to any significant degree.

The present study cohort was followed for $11 \mathrm{yrs}$. At baseline, the study cohort was between 15-59 yrs of age, so the results are mostly relevant to adult-onset asthma. The increase in asthma in the study by SUNYER et al. [30] covers the period from birth to 230 yrs of age, thus the comparative study may not be directly comparable. However, the exact same mechanisms would operate to cause a recall bias.

It is likely that recall bias in the retrospective study can explain a significant part of the bias found in the analysis of trends by year of birth. There is increasing missing data in the questions on asthma diagnosis and asthma onset by earlier year of birth (table 4), but much more so in the retrospective study than in the prospective study. This is not only likely to reflect that some of the older subjects were likely to have forgotten their age at onset, but also that the recall was poorer in general among the older subjects. This was probably because of the longer time span involved.

The high proportion of missing answers to the questions on bronchitis, and the undefined validity of this question, make the authors cautious of any conclusions regarding this outcome. There is likely to be some confounding of the "asthma diagnosis" with chronic obstructive pulmonary disease at $>45$ yrs. However, this should not influence the comparison between the retrospective and the prospective study.

Given the uncertainty of a retrospective asthma diagnosis, what about a retrospective analysis of symptom incidence? The authors did not ask for age at onset of any symptoms, and they are unaware of any asthma studies that have. In light of the recall bias and its mechanisms shown for asthma diagnosis, it is likely that the findings concerning symptoms would either be the same or worse.

To conclude, somewhat comparable asthma incidence in prospective and retrospective studies was found. However, retrospective analysis of trends in asthma incidence by year of birth was severely biased compared with the prospective analysis. Retrospective evidence for an increasing trend in asthma incidence should be treated with scepticism.

\section{References}

1. Ninan TK, Russell G. Respiratory symptoms and atopy in Aberdeen schoolchildren: evidence from two surveys 25 years apart. BMJ 1992; 304: 873-875.

2. Aberg N, Hesselmar B, Aberg B, Eriksson B. Increase of asthma, allergic rhinitis and eczema in Swedish schoolchildren between 1979 and 1991. Clin Exp Allergy 1995; 25: 815-819.

3. Nystad W, Magnus P, Gulsvik A. Increasing risk of asthma without other atopic diseases in school children: a repeated cross-sectional study after 13 years. Eur J Epidemiol 1998; 14: 247-252.

4. Downs SH, Marks GB, Sporik R, Belosouva EG, Car NG, Peat JK. Continued increase in the prevalence of asthma and atopy. Arch Dis Child 2001; 84: 20-23.

5. Kuehni CE, Davis A, Brooke AM, Silverman M. Are all wheezing disorders in very young (preschool) children increasing in prevalence? Lancet 2001; 357: 1821-1825.

6. Hansen EF, Rappeport Y, Vestbo J, Lange P. Increase in prevalence and severity of asthma in young adults in Copenhagen. Thorax 2000; 55: 833-836.

7. Mannino DM, Homa DM, Pertowski CA, et al. Surveillance for Asthma - United States, 1960-1995. MMWR 1998; 47: 128.

8. Peat JK, Haby M, Spijker J, Berry G, Woolcock AJ. Prevalence of asthma in adults in Busselton, Western Australia. BMJ 1992; 305: 1326-1329.

9. Rimpela AH, Savonius B, Rimpela MK, Haahtela $\mathrm{T}$. 
Asthma and allergic rhinitis among Finnish adolescents in 1977-1991. Scand J Soc Med 1995; 23: 60-65.

10. Senthilselvan A. Prevalence of physician-diagnosed asthma in Saskatchewan, 1981 to 1990. Chest 1998; 114: 388-392.

11. Tirimanna PR, van Schayck CP, den Otter JJ, et al. Prevalence of asthma and COPD in general practice in 1992: has it changed since 1977? Br J Gen Pract 1996; 46: 277-281.

12. Upton MN, McConnachie A, McSharry C, et al. Intergenerational 20 year trends in the prevalence of asthma and hay fever in adults: the Midspan family study surveys of parents and offspring. BMJ 2000; 321: 88-92.

13. Vollmer WM, Buist AS, Osborne ML. Twenty year trends in hospital discharges for asthma among members of a health maintenance organization. J Clin Epidemiol 1992; 45: 9991006.

14. Vollmer WM, Osborne ML, Buist AS. 20-year trends in the prevalence of asthma and chronic airflow obstruction in an HMO. Am J Respir Crit Care Med 1998; 157: 1079-1084.

15. Linneberg A, Nielsen NH, Madsen F, Frolund L, Dirksen A, Jorgensen T. Secular trends of allergic asthma in Danish adults. The Copenhagen Allergy Study. Respir Med 2001; 95 : 258-264.

16. Brogger J, Bakke P, Eide GE, Johansen A, Andersen A, Gulsvik A. Long-term changes in adult asthma prevalence. Eur Respir J 2003; 21: 468-472.

17. Matricardi PM, Bonini S. Why is the incidence of asthma increasing? In: Johnston SL, Holgate ST, eds. Asthma: Critical Debates. London, Blackwell Science, 2002; pp. 3-17.

18. Mitchell EA. International trends in hospital admission rates for asthma. Arch Dis Child 1985; 60: 376-378.

19. Morrison DS, McLoone P. Changing patterns of hospital admission for asthma, 1981-97. Thorax 2001; 56: 687-690.

20. Ayres JG, Noah ND, Fleming DM. Incidence of episodes of acute asthma and acute bronchitis in general practice 1976-87. Br J Gen Pract 1993; 43: 361-364.

21. Fleming DM, Sunderland R, Cross KW, Ross AM. Declining incidence of episodes of asthma: a study of trends in new episodes presenting to general practitioners in the period 1989-98. Thorax 2000; 55: 657-661.

22. Reijula K, Haahtela T, Klaukka T, Rantanen J. Incidence of occupational asthma and persistent asthma in young adults has increased in Finland. Chest 1996; 110: 58-61.

23. Burney PG. Asthma mortality in England and Wales: evidence for a further increase, 1974-84. Lancet 1986; 2: 323-326.

24. Arrighi HM. US asthma mortality: 1941 to 1989. Ann Allergy Asthma Immunol 1995; 74: 321-326.

25. Beasley R, Pearce N, Crane J. International trends in asthma mortality. In: Chadwick DJ, Cardew G, eds. The Rising Trends in Asthma. Chichester, Wiley (Ciba Symposium), 1997; pp. 140-156.

26. Cooreman J, Segala C, Henry C, Neukirch F. Trends in asthma-induced mortality in France from 1970-90. Tuber Lung Dis 1994; 75: 182-187.

27. Foucard T, Graff-Lonnevig V. Asthma mortality rate in Swedish children and young adults 1973-88. Allergy 1994; 49: 616-619.

28. Yunginger JW, Reed CE, $\mathrm{O}^{\prime}$ Connell EJ, Melton LJD, $\mathrm{O}^{\prime}$ Fallon WM, Silverstein MD. A community-based study of the epidemiology of asthma. Incidence rates, 1964-1983. Am Rev Respir Dis 1992; 146: 888-894.
29. Huovinen E, Kaprio J, Laitinen LA, Koskenvuo M. Incidence and prevalence of asthma among adult Finnish men and women of the Finnish Twin Cohort from 1975 to 1990, and their relation to hay fever and chronic bronchitis. Chest 1999; 115: 928-936.

30. Sunyer J, Anto JM, Tobias A, Burney P. Generational increase of self-reported first attack of asthma in fifteen industrialized countries. European Community Respiratory Health Study (ECRHS). Eur Respir J 1999; 14: 885-891.

31. de Marco R, Locatelli F, Sunyer J, Burney P. Differences in incidence of reported asthma related to age in men and women. A retrospective analysis of the data of the European Respiratory Health Survey. Am J Respir Crit Care Med 2000; 162: $68-74$.

32. de Marco R, Locatelli F, Cerveri I, Bugiani M, Marinoni A, Giammanco G. Incidence and remission of asthma: a retrospective study on the natural history of asthma in Italy. J Allergy Clin Immunol 2002; 110: 228-235.

33. Bakke P, Gulsvik A, Lilleeng $\mathrm{P}$, Overå O, Hanoa R, Eide GE. Postal survey on airborne occupational exposure and respiratory disorders in Norway: causes and consequences of non-response. J Epidemiol Community Health 1990; 44: 316-320.

34. Eagan T, Eide G, Gulsvik A, Bakke P. Nonresponse in a community cohort study. Predictors and consequences for exposure-disease associations. J Clin Epidemiol 2002; 55: 775.

35. Brogger J, Bakke P, Eide GE, Gulsvik A. Comparison of telephone and postal survey modes on respiratory symptoms and risk factors. Am J Epidemiol 2002; 155: 572-576.

36. Eagan TM, Gulsvik A, Eide GE, Bakke PS. Occupational airborne exposure and the incidence of respiratory symptoms and asthma. Am J Respir Crit Care Med 2002; 166: 933-938.

37. Eagan TM, Bakke P, Eide GE, Gulsvik A. Incidence of asthma and respiratory symptoms by sex, age and smoking in a community study. Eur Respir $J$ 2002; 19: 599-605.

38. Brogger J, Bakke P, Eide GE, Gulsvik A. Contribution of follow-up of non-responders to prevalence and risk estimates. A Norwegian respiratory health survey. Am $J$ Epidemiol 2003; 157: 558-566.

39. Greenland S. Dose-response and trend analysis in epidemiology: alternatives to categorical analysis. Epidemiology 1995; 6: 356-365.

40. Harrell FE Jr. 2.4 Relaxing linearity assumption for continuous predictors. In: Regression Modeling Strategies: With Applications to Linear Models, Logistic Regression, and Survival Analysis. 1st Edn. Springer-Verlag, New York, 2001; pp. 16-26.

41. Holford TR. Age-period-cohort analysis. In: Gail MH, Benichou J, eds. Encyclopedia of Epidemiologic Methods. Chichester, Wiley, 2000; pp. 17-35.

42. Toren K, Hermansson BA. Incidence rate of adult-onset asthma in relation to age, sex, atopy and smoking: a Swedish population-based study of 15813 adults. Int $J$ Tuberc Lung Dis 1999; 3: 192-197.

43. Dodge RR, Burrows B. The prevalence and incidence of asthma and asthma-like symptoms in a general population sample. Am Rev Respir Dis 1980; 122: 567-575.

44. Strachan DP, Butland BK, Anderson HR. Incidence and prognosis of asthma and wheezing illness from early childhood to age 33 in a national British cohort. BMJ 1996; 312: 1195-1199. 